\title{
UMA NOVA ESPÉCIE DE BALLONISCUS BUDDE-LUND (CRUSTACEA, ISOPODA, BALLONISCIDAE) DO SUL DO BRASIL
}

\author{
Paula Beatriz de Araujo 1, 3 \\ Cristina M. Loyola Zardo ${ }^{2}$
}

\begin{abstract}
A NEW SPECIIES OH BALIONISCUS BUIDDF-LUND (CRUSTACIA. ISOPODA. BALIONISCIDAE) FROM SOUTHERn BrAzII. Balloniscus glaber. sp.n. is described from Rio Grande do Sul. Brazil.

KEY WORDS. Isopoda. Oniscidae. Balloniscus glaber sp.n., taxonomy. Southern Brazil
\end{abstract}

No curso das investigaçōes sobre a fauna de Isopoda terrestre do Brasil meridional foi identificada uma espécie de Balloniscus Buddle-Lund, 1908 ainda não descrita. O único representante da família com registro para a área de estudo, até o presente, é B. sellowii (Brandt, 1833), espécie estudada por LEMOS DE CASTRO (1976).

O material coletado, proveniente de várias localidades do Rio Grande do Sul, encontra-se depositado no Setor de Carcinologia, Departamento de Zoologia, Universidade Federal do Rio Grande do Sul (UFRGS).

\section{Balloniscus glaber, sp.n.}

Figs 1-17

Holótipo macho. BRASIL, Rio Grande do Sul: Rio Grande (Vieira, $32^{\circ} 04^{\prime} 48^{\prime \prime} \mathrm{S}$ e $52^{\circ} 09^{\prime} 18^{\prime \prime} \mathrm{O}$, floresta de planície de solo turfoso, sob folhas), 05-IV-1991, P.B. Araujo e C.M.L. Zardo, leg. (UFRGS 01799H).

Parátipos. Brasil, Rio Grande do Sul: Sapucaia do Sul (Jardim Zoológico, em tronco podre), quatro machos, seis fêmeas, 13-V-1991, P.B. Araujo leg. (UFRGS 01796P); Rio Grande (Cassino, sob folhas), cinco machos, quatro fềmeas, uma fêmea ovígera, 26-VIII-1994, C.M.L. Zardo e A.C. Oliveira leg. (UFRGS 01992P); Rio Grande (terreno baldio), dois machos, 03-V-1991, A.C. Oliveira leg. (UFRGS 01993P); Rio Grande (Estação Ecológica do Taim, sob folhas), dois machos, 01-XII-1989, C.M.L. Zardo leg. (UFRGS 01994P); Sapu-

1) Escola Técnica de Coméreio, Universidade Federal do Rio Grande do Sul. Rua Ramiro Barcelos 2777. 9(0)35-(0)7 Porto Alegre. Rio Grande do Sul. Brasil.

2) Departamento de Ciências Morfo-Biológicas. Fundação Universidade do Rio Grande. Caixa Postal 474, 96201-90(0) Rio Grande. Rio Grande do Sul. Brasil.

3) Departamento de Zoologia, Instituto de Biociências, Universidade Federal do Rio Grande do Sul. Avenida Paulo Gama 40. 90(40-(060) Porto Alegre, Rio Grande do Sul, Brasil 


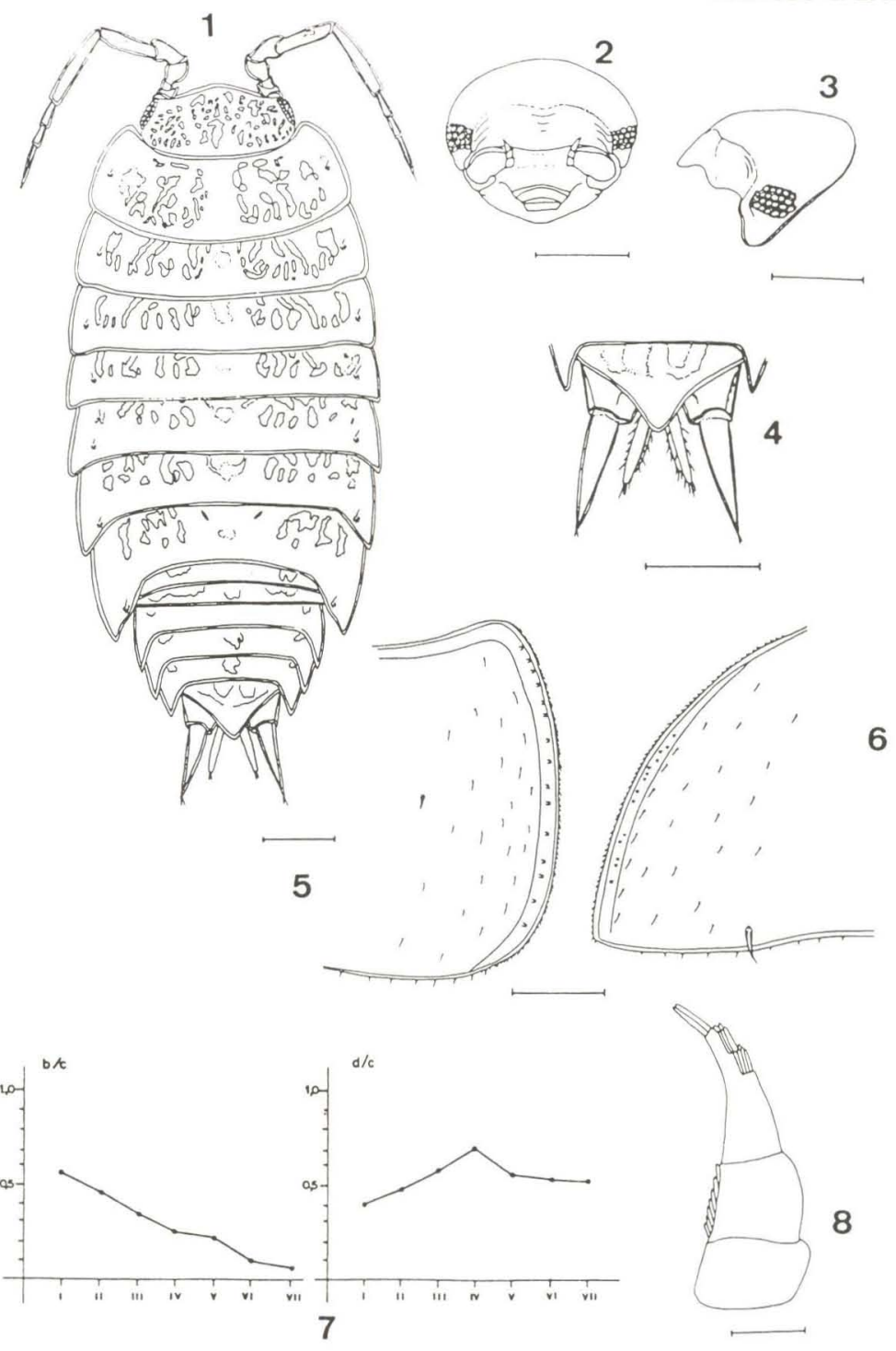

Figs 1-8. Balloniscus glaber, sp.n.; (1) Macho (holótipo), vista dorsal; (2) cabeça em vista frontal; (3) cabeça em vista lateral; (4) telso e urópodos; (5) borda do pereionito I; (6) borda do pereionito VII; (7) posição dos nódulos laterais com relação às margens dos pereionitos I-VII, (b/c) margem posterior, (d/c) margem lateral; (8) antênula. Escalas: (1-4) $1 \mathrm{~mm} ;(5-6) 0,4 \mathrm{~mm} ;(8) 0,1 \mathrm{~mm}$.

caia do Sul (Jardim Zoológico, sob folhas), três machos, cinco fêmeas 15-IX-1991, P.B. Araujo leg. (UFRGS 01797); Osório (Morro Borússia, em vegetação nativa, sob folhas), uma fêmea ovígera, 09-III-1991, P.B. Araujo leg. (UFRGS 01473); Osório (Morro Borússia, em vegetação nativa, sob folhas), um macho, quatro 
fêmeas, 10 jovens, 19-V-1991, P.B. Araújo e F.M. Bento leg. (UFRGS 01755); Triunfo (COPESUL, coletado com peneira de solo), uma fêmea, 12-V-1991, A.B. Bonaldo leg. (UFRGS 01800); Viamão (Itapuã, Parque Estadual de Itapuã, sob folhas e pedras), oito machos, oito fêmeas, uma fêmea ovígera, um jovem, 20-IX-1991, P. B. Araujo leg. (UFRGS 01798); Barra do Ribeiro (Horto Florestal Barba Negra, vegetação nativa, sob folhas), dois machos, duas fêmeas, 27-VII1991, P.B. Araujo legl. (UFRGS 01802); Rio Grande (Vieira, floresta de planície de solo turfoso, sob folhas), dois machos, quatro jovens, 05-IV-1991, P. B. Araujo e C.M.L. Zardo leg. (UFRGS 01801).

Localidade-tipo. Brasil, Rio Grande do Sul: Rio Grande (32"02'12"S e $52^{\circ} 05^{\prime} 52^{\circ} \mathrm{O}$, coordenadas do centro da cidade). Cidade de clima subtropical marítimo, situada a dois metros acima do nível do mar.

Diagnose. Tegumento do corpo de aspecto glabro e brilhante, presença de poucas cerdas curtas. Linha frontal presente; linha supra-antenal sinuosa; olhos com 20-22 omatídios. Nódulos laterais do pereionito VII deslocados da extremidade para dentro, distantes da linha marginal lateral. Telso triangular com a ponta aguda que ultrapassa a extremidade distal do protopodito dos urópodos. Isquio do pereiópodo 7 do macho pouco cerdoso.

Descrição. Medidas (maiores dimensões nos lotes examinados): macho: 13,37x5,68mm; fềmea: $13,50 \times 5,25 \mathrm{~mm}$.

Coloração. Padrões diversificados; pigmentação variando de castanho escuro a claro, às vezes avermelhada ou acinzentada, variegada em maior ou menor intensidade com manchas amarelas; faixa mediana dorsal longitudinal escurecida, frequentemente com manchas claras desde o pereionito I até o final do pleon; geralmente com faixa longitudinal escurecida na borda dos pereionitos; antenas de cor castanha uniforme (algumas vezes o segundo artículo do pedúnculo é esbranquiçado).

Características gerais. Cabeça pouco envolvida pelo pereionito I. Linha frontal presente delimitando lobos laterais pouco acentuados em frente aos olhos (Figs 1, 3); linha supra-antenal sinuosa (Fig. 2). Olhos com 20-22 omatídios. Epímeros dos pereionitos V, VI e VII projetados para trás com ponta aguda. Pleon estreitando-se gradualmente. Telso triangular com ápice agudo, ultrapassando a extremidade distal do protopodito dos urópodos (Fig. 4).

Tegumento. Superfície lisa, brilhante com tricornes curtos e pouco numerosos. Nódulos laterais com a maior relação d/c no pereionito IV (Fig. 7) e os do pereionito VII deslocados da extremidade para dentro (Fig. 6); posição das coordenadas b/c e d/c como na figura 7 . Cerca de 15 poros glandulares na borda dos pereionitos (Figs 5, 6). pereiópodos com cerdas, espinhos e "trichia".

Apêndices. Artículo distal da antênula com cerca de 12 estetascos, sendo dois apicais (Fig. 8). Antena, quando distendida para trás, atinge o pereionito II; flagelo do mesmo tamanho que o artículo IV do pedúnculo. Exito da maxílula com $4+6$ (quatro fendidos) dentes (Fig. 10). Maxilípodo com endito quadrangular armado de um dentículo sobreposto a outro na borda distal interna e outro na borda superior externa (Fig. 9). Exópodo dos urópodos cerca de 1,5 vezes mais longo que o telso, endópodos com metade do comprimento dos exópodos (Fig. 4). 

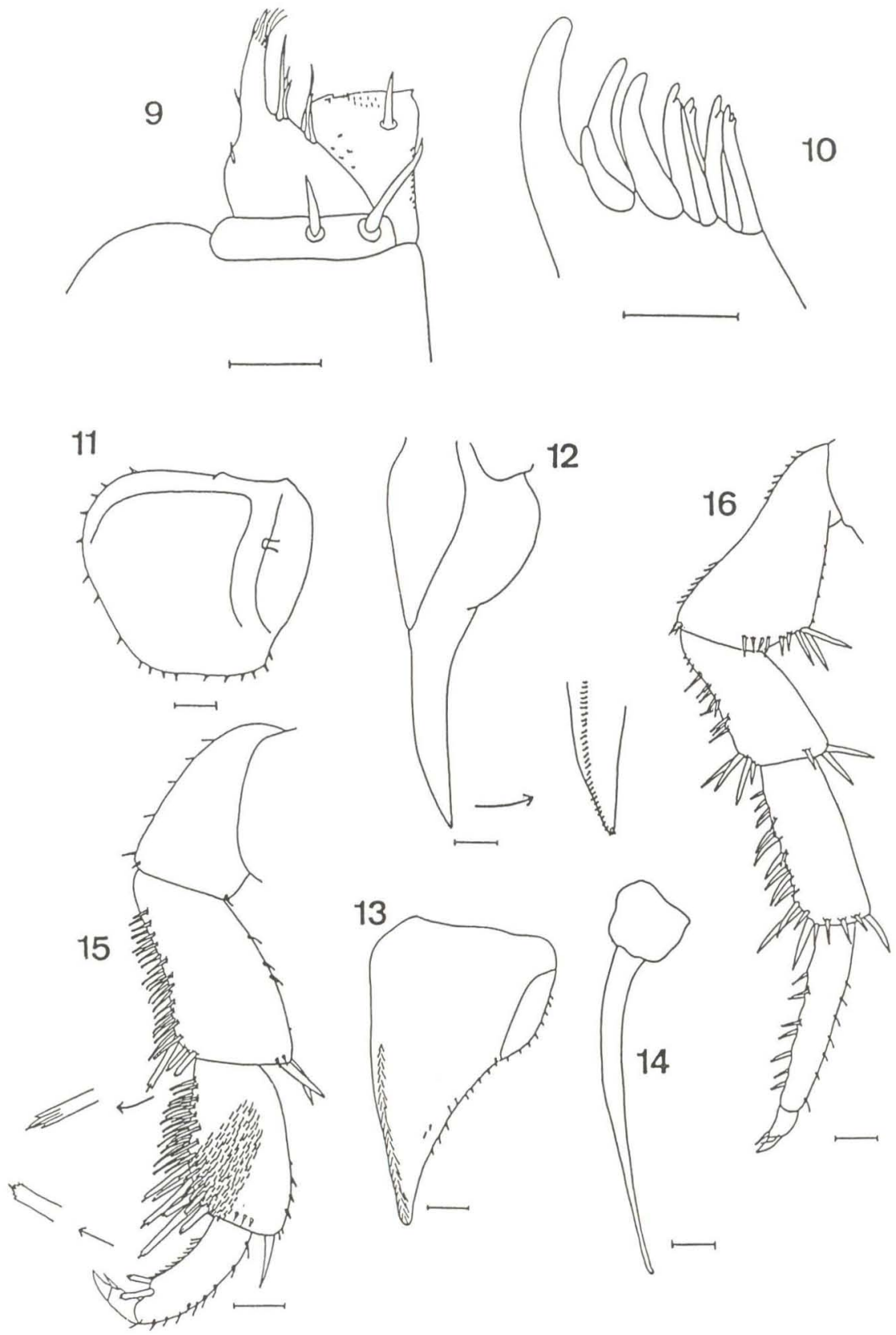

Figs 9-16. Balloniscus glaber, sp.n.. (9) Maxilípodo; (10) exito da maxilula; (11) exópodo do pleópodo I; (12) endópodo do pleópodo I; (13) exópodo do pleópodo II; (14) endópodo do pleópodo I; (15) pereiópodo 1; (16) pereiópodo 7. Escalas: (9-10) 0,1mm; (11-16) $0,2 \mathrm{~mm}$. 
Dimorfismo sexual. Macho com pereiópodo 1 com mero e carpo providos de numerosas cerdas (Fig. 15); pereiópodo 7 sem dimorfismo aparente, macho e fêmea não possuem um conjunto de pequenas cerdas no ísquio (Fig. 16). Pleópodo I com exópodo quadrangular e linha marginal distal reta (Fig. 11) e endópodo alongado, provido de pêlos e de uma série de pequenas cerdas na extremidade distal (Fig. 12); pleópodo II com exópodo subtriangular (Fig. 13) e endópodo com a extremidade distal rombuda (Fig. 14).

Discussão. A família Balloniscidae, instituída por VANDEL (1963) para abrigar os gêneros Balloniscus Budde-Lund, 1908 e Plataoniscus Vandel, 1963, diferencia-se de Philosciidae pela presença de pulmões pleopodais nos cinco pares de pleópodos. Os pulmões pleopodais, devido a sua função respiratória, são estruturas importantes que devem ser consideradas na classificação dos isópodos terrestres. Em Balloniscidae eles podem apresentar-se com ramificações arbustiformes (como em Plataoniscus) ou sem ramificaçōes arbustiformes (como em Balloniscus), consistindo, então, na principal caracteristica diferencial entre os gêneros, uma questão já levantada por RECA (1970). Neste caso, a presença ou ausência de linha frontal deixa de ser uma característica diagnóstica de gênero, conforme proposto por VANDEL (1963).

Balloniscus glaber distingue-se de Balloniscus sellowii (Brandt, 1833) por apresentar tegumento do corpo de aspecto glabro e brilhante, presença de poucas cerdas curtas; linha frontal (Fig. 2); telso triangular com ápice agudo que ultrapassa a extremidade distal do protopodito dos urópodos (Fig. 4); nódulo lateral VII deslocado da extremidade para dentro, distante da linha marginal lateral (Fig. 6); cerca de 15 poros glandulares (Figs 5, 6): dentículos do endito do maxilípodo sobrepostos um ao outro (Fig. 9); exópodos dos urópodos cerca de 1,5 vezes mais longos que o telso (Fig. 4); pereiópodo 7 do macho sem concentração de pequenas cerdas no ísquio (Fig. 16); exópodo do pleópodo I do macho com a linha marginal distal reta (Fig. 11). Enquanto que em B. sellowii o tegumento dorsal é provido de numerosas cerdas, bastante visiveis; linha frontal ausente; telso triangular com ápice arredondado não ultrapassando a extremidade distal do protopodito dos urópodos; nódulo lateral VII na borda inferior do epímero, próximo à linha marginal lateral; com mais de 30 poros glandulares; dentículos do endito do maxilípodo um subsequente ao outro; exópodos dos urópodos com mais de duas vezes o comprimento do telso; pereiópodo VII do macho com concentração pequenas de cerdas no ísquio; exópodo do pleópodo I do macho com a linha marginal distal curva.

Etimologia. O nome refere-se ao tegumento do corpo de aspecto glabro e brilhante.

Dados comportamentais. Os indivídos desta espécie locomovem-se rapidamente e escondem-se com facilidade sob o substrato; quando tocados "fingem-se" de mortos, ficando com o corpo levemente encurvado e, em geral, com os pereiópodos voltados para cima.

Distribuição. Balloniscus glaber foi encontrada somente no leste do Rio Grande do Sul, planície costeira, com limites norte registrado em Osório e sul em Rio Grande (Fig. 17). 


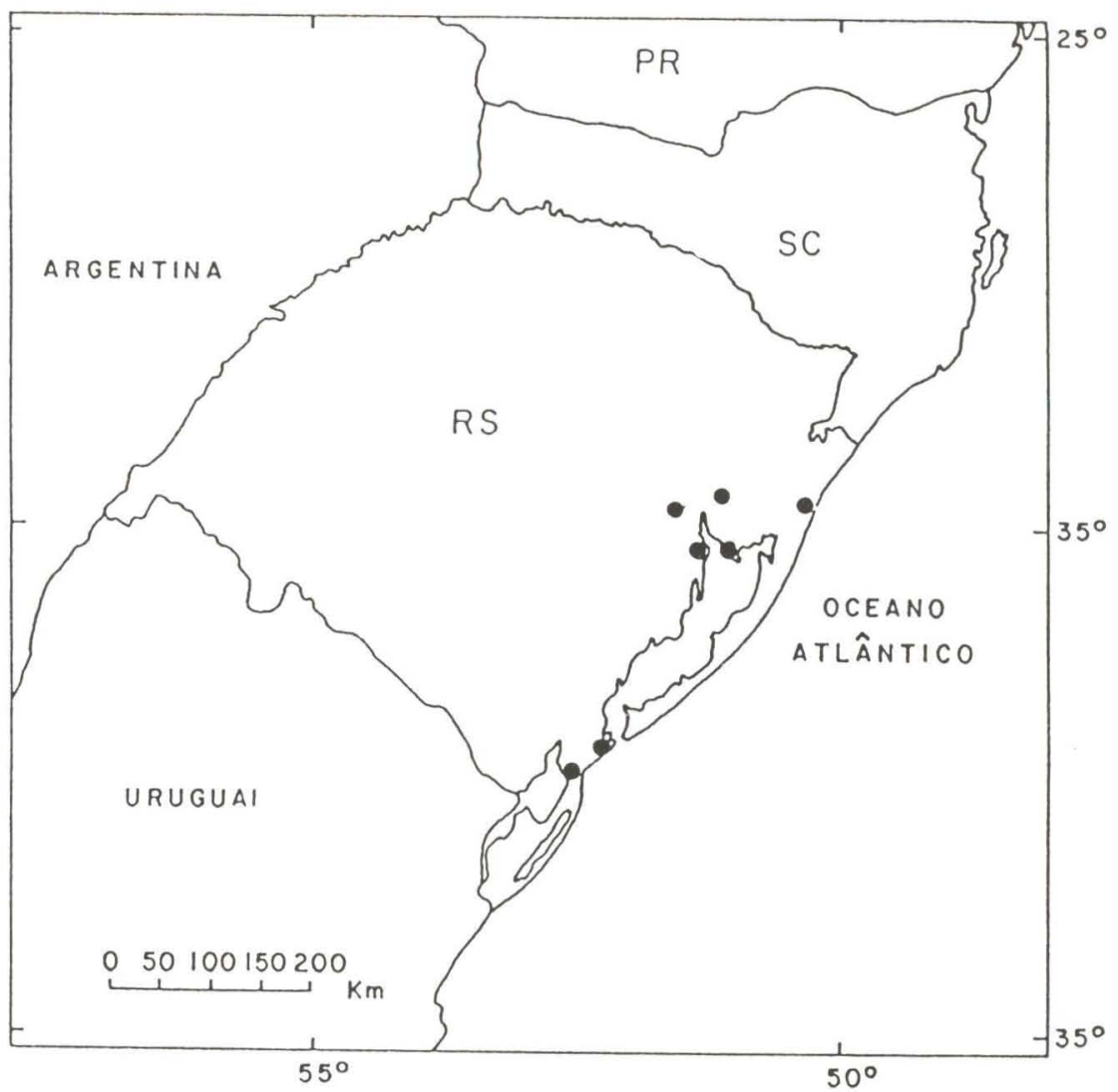

Fig. 17. Registros de ocorrência de Balloniscus glaber, sp.n..

\section{REFERÊNCIAS BIBLIOGRÁFICAS}

Lemos DE CASTRO, A. 1976. Considerações sobre a sinonímia e distribuição de Balloniscus sellowii (Brandt, 1833) (Isopoda, Balloniscidae). Rev. Bras. Biol. 36 (2): 391-196.

RECA, A.R. 1970. Oniscoideos argentinos. I. Sobre la posición sistemática de

Philoscia argentina Giambiagi, 1939 (Crustacea, Isopoda). Physis 29 (79): 423-429.

VANDEL, A. 1963. Isopodes terrestres recueillis en Amérique du Sud par Claude Delamare Deboutteville, p.63-100. In: C.D. DedouteviLLE \& E.H. RAPOPORT (Eds). Biologie de l'Amérique Australe, Études sur la Faune du Sol. Paris, CNRS, CNIT, vol. 2, 657p. 